\title{
Autoridades sob o olhar de Datena: uma análise do discurso do programa Brasil Urgente ${ }^{1}$
}

\author{
Michele Negrini $^{2}$
}

\section{Resumo}

O objetivo deste estudo é fazer uma reflexão sobre o discurso do apresentador José Luiz Datena do Brasil Urgente da Rede Bandeirantes. Datena, durante a apresentação do programa, tem uma postura opinativa, capaz de analisar e julgar as atitudes das autoridades competentes e os acontecimentos da sociedade. No decorrer do Brasil Urgente, o apresentador enfatiza ao público as suas opiniões acerca dos fatos e expõe os detalhes mais íntimos da vida das pessoas envolvidas nos casos apresentados. Tais evidências no Brasil Urgente o tornam um objeto rico para estudos. Tomamos como suporte metodológico a análise do discurso de linha francesa. Como objeto de pesquisa, analisamos uma edição do programa, que foi ao ar no mês de maio de 2006.

Palavras-chaves: Análise de discurso; produção de sentidos; espetacularização

\section{Abstract}

The objective of this study is to make a reflection about the speech of the presenter José Luiz Datena from the broadcast Brasil Urgente from Rede Bandeirantes. Datena, during the presentation of the program, has an opinative posture, being able to analyze and judge the attitudes of competent authorities and what happens in society. Along Brasil Urgente, the presenter emphasizes to the public his opinions about the facts and exposes the most intimate details of the lives of people involved in the cases presented. Such evidences in Brasil Urgente make him an object rich for studies. We have taken as methodological support the discourse analysis from the french line. As object of research, we analyzed one edition of the program, which was presented in May 2006.

Keywords: Discourse analysis; production of meanings; spectacularization 
O Brasil Urgente, da Rede Bandeirantes, está no ar desde o dia três de dezembro de dois mil e um. O programa $^{3}$ é apresentado por José Luiz Datena ${ }^{4}$, que, através de uma linguagem coloquial e opinativa, conduz o programa como um juiz hábil a avaliar os acontecimentos sociais e as atitudes das autoridades competentes. A estrutura do telejornal é toda baseada na maestria do apresentador, que é capaz de chamar a atenção no ar dos membros de sua produção.

O Brasil Urgente tem sua pauta voltada à cobertura de uma diversidade de temáticas, como: segurança, saúde, trabalho e comportamento ${ }^{5}$. De tal forma a mesclar o jornalismo investigativo à espetacularização, mostrando fatos corriqueiros e não solucionados pelos órgãos competentes. Fatos violentos têm espaço amplo durante o Brasil Urgente, sempre recebendo atenção especial do apresentador, o qual se utiliza das reiterações para destacar o que acha relevante. O apresentador, durante o programa, caracteriza o Brasil Urgente como dinâmico, por ser voltado à prestação de serviços à comunidade e à resolução de problemas sociais.

Um dos destaques do telejornal é a forma como o apresentador conduz o programa, portando-se de forma completamente opinativa. O tempo destinado à apresentação das matérias e aos comentários do apresentador é um fator que diferencia o Brasil Urgente da maior parte dos telejornais. As opiniões de Datena acerca dos fatos são de fácil identificação. Expressões como "filhinho de papai”, "vagabundo" e "sem vergonha" fazem parte do vocabulário do jornalista, evidenciando o seu caráter opinativo e a sua parcialidade quanto aos acontecimentos sociais. A postura e as gesticulações de Datena também são destaques. Ao estar em pé, ganha agilidade em suas performances e dá mais ênfase à sua fala.

\section{Televisão e espetáculo}

A televisão é um veículo de comunicação que, além de ser fonte de distração, de conhecimento e de informação, une as pessoas e proporciona temas para que elas troquem idéias e debatam, tornando-se, assim, um vínculo entre elas.

Na atualidade, a TV tem passado por contínuas mudanças na sua programação e no seu modo de enfocar os conteúdos apresentados, que implicam na exaltação de programas com conteúdos espetacularizados e, algumas vezes, sem relações com o contexto social. A espetacularização é um ingrediente presente inclusive na grade de jornalismo de muitas emissoras, as quais, mesmo que de forma sutil, apresentam programas shows como forma de chamar a atenção do público. Dentro desta perspectiva, pode-se salientar desde o extinto "Aqui Agora", exemplo clássico de exaltação dos acontecimentos mais sensacionais e que chamam a atenção das pessoas, até os telejornais vistos como padrão e de referência, o que é o caso do Jornal Nacional. Enquanto no Aqui Agora a espetacularização ocorria de forma mais escrachada e os repórteres abusavam de gesticulações e 
entonações especificamente exageradas, no Jornal Nacional, pode-se considerar a exaltação do casal de apresentadores William Bonner e Fátima Bernardes como uma forma mais delicada de atração do público para o programa e de espetacularização. Um conjunto de elementos, como dramatizações e especulações sobre a vida particular das pessoas envolvidas nos casos apresentados, misturados com itens do jornalismo ocupam constantemente o espaço televisivo, gerando programas de difícil classificação quanto ao gênero. Tratamos tais programas, que podem ser exemplificados pelo Brasil Urgente - objeto deste estudo - como híbridos de jornalismo e dramaturgia.

A televisão pode ser considerada o meio hegemônico da última metade do século XX (MACHADO, 2000). Nos dias de hoje, a TV tem veiculado os mais variados formatos e estilos de programas. Desta forma, utilizando-se de suas características próprias, como o uso de imagem acoplada ao som, que já a tornam espetacular, a TV disponibiliza considerável espaço na apresentação de programas shows. Como diz Sodré (1987: 8-9), comentando a importância da imagem:

“A imagem opera mutações na estrutura psíquica e nos modos de percepção do indivíduo contemporâneo. Daí, a importância ou o grande vulto da televisão. Esta não é um simples "meio de informação" que, ao lado de outros, veicularia conteúdos específicos. Trata-se, na verdade, de uma estrutura, uma forma de saturação informacional do meio ambiente na sociedade pós-moderna, gerida cada vez mais pela tecnologia eletrônica e pela organização tecnoburocrática".

O fundamental na televisão é o fato de ela não ser só imagem, de ela ser laço social. Por mais que a imagem seja a marca da televisão, não se pode ignorar a dimensão social do veículo. No momento em que as pessoas comentam o que viram na tela, elas estão se integrando socialmente. A televisão é uma forma de abertura para o mundo, é muito difícil alguém ficar indiferente diante das emissões televisivas (WOLTON, 1996).

A televisão, como veículo difusor de informações, que leva ao público novidades, imagens, divertimento, publicidades, é fundamental no processo de produção de sentidos e na formação do imaginário. Ela amplia a própria realidade, dando espaço para um ambiente simulado, espetacularizado. A televisão, no momento em que vai noticiar um fato e quer seduzir o espectador, utiliza-se de numerosos modos de comunicação e recursos, entre os quais encontra-se a dramatização ou simulação. Um dos principais motivos para se dramatizar a notícia é torná-la urgente, mesmo que no dia seguinte não seja mais lembrada e não tenha mais relevância. A tendência à dramatização é percebida não só no tratamento da notícia como na sua escolha, pois são priorizados crimes, tragédias, violência, morte, miséria. Para dar mais ênfase ao fato que está sendo mostrado, um recurso utilizado é a encenação de testemunhos, que podem ser dados por pessoas anônimas (SILVA, 2002). 
Através da dramatização há a possibilidade de criação de uma relação de encantamento com o telespectador (ROSÁRIO, 2001). A dramatização reforça o realismo dos fatos apresentados e faz com que as pessoas que estão frente à tela tenham a confirmação da veracidade do conteúdo da informação:

“Uma forte estratégia de sedução utilizada pelos textos televisivos é a simulação, consubstanciada não como representação, mas como simulacro, como aparência sem realidade. Essa estratégia encanta e presenteia o espectador com o sonho e com a fantasia. A simulação permite tudo, ou quase tudo. Através da violação da fronteira da realidade é possível mais do que representar, do que "fazer-de-conta", é possível quase vivenciar aquilo que não tem existência e, dessa maneira, estimular o espectador a recorrer à sua capacidade de fantasiar, de preencher vazios de sentidos com prazeres; de preencher os tristes vazios do mundo com sonhos encantados" (ROSÁRIO, 2001: 85).

A simulação cria a ilusão de que o fato está acontecendo ao vivo, no momento e que os detalhes picantes são verdadeiros. Com a utilização da imagem e dos sons integrados com a palavra, a televisão oferece ao receptor a legitimação do que está sendo transmitido. As pessoas conseguem facilmente identificar personagens conhecidos na televisão e informações vistas neste meio. A imagem, elemento diferencial da simulação televisiva, é essencial no processo de espetacularização dos produtos midiáticos. Squirra (1993) relaciona a televisão com a espetacularização: "Desde o seu advento, a televisão tem sido o veículo preferido na disseminação de informações e peça fundamental para o entretenimento das sociedades" (SQUIRRA, 1993: 9). Fischer (1984: 65) concorda:

Na TV, o público encontra todo tipo de shows: desde aqueles que, através de reportagens, mostram o lado espetacular da vida, o sensacionalismo, os fatos insólitos, até os musicais e os programas de competições com a participação de auditório. Enquanto nas novelas, filmes e desenhos animados, os espectadores assistem à narração de uma história, nos shows recebem a sucessão de imagens e sons em forma de mosaico.

O formato espetacular pode ser considerado uma fórmula capaz de atrair os mais diversificados públicos. Devido à dimensão adquirida pelos programas espetacularizados no contexto social, a inserção destes programas na grade das emissoras já é um item obrigatório (BUCCI, 1993). Na concorrência por audiência, o espetáculo não pode ficar de fora:

“Aos poucos, a televisão permitiu que o universo policial se incorporasse ao seu dia-a-dia. Não tinha escolha. No negócio do entretenimento, ao menos no Brasil, a espetacularização do mundo-cão deixou de ser um item opcional para ser obrigatório. Assim, o tabu do mundo-cão dentro do vídeo - que já havia sido subvertido com tentativas isoladas - foi quebrado no final da década de 80”. (BUCCI, 1993: 101-102).

Nas sociedades modernas, a televisão, com a disseminação do espetacular, cumpre funções simbólicas comparáveis aos mitos nas sociedades primitivas. A televisão pode ser analisada como um veículo de fascinação: “As luzes da TV recebem o nome que era dado às luzes do teatro: as luzes da TV são mágicas. Têm o poder de parar o trânsito, de modificar emoções arrancando lágrimas, quando não era para tanto e seduzindo 
aquele que era para ser apenas um figurante. O direito aos 15 minutos de fama (ou segundos, para a televisão) a que o artista plástico norte-americano Andy Wharol se referia são buscados com fúria pelos anônimos" (PINTO, 1998: 64).

Embora concordemos com a idéia de que a televisão tem poderes sobre o telespectador, neste trabalho nos filiamos a Wolton, que diz que a televisão pode influenciar o público, mas não o manipula. “[...] o público nunca é passivo ou alienado. Ele pode ser influenciado, principalmente por programas de baixa qualidade, mas falar em alienação suporia a perda do seu livre-arbítrio" (WOLTON, 2003: 67).

\section{Análise do discurso francesa}

A Análise do Discurso (AD) de perspectiva francesa, que surge especialmente a partir das sistematizações de Michel Pêcheux sobre conceitos fundadores de Mikhail Bakhtin e Michel Foucault, é uma linha de investigação que tem por objeto textos, que são ao mesmo tempo lingüísticos e históricos. O discurso articula a língua com a história, sendo ele mesmo um "efeito de sentidos" - que existiam antes dele e que vêm conformá-lo naquele contexto específico, enunciado por aqueles atores determinados, naquele momento histórico.

O texto como objeto de pesquisa implica que se tome a Análise do Discurso como um quadro de referência conceitualmente organizado, mas metodologicamente aberto. É preciso ouvir com atenção o que dizem - e como dizem - os textos que o analista tomou como objeto. A AD tem uma preocupação que ultrapassa a hermenêutica. É preciso ir além da interpretação dos sentidos de um texto: é preciso entender como o discurso funciona. Que lógica o movimenta, que elementos são repetidos, que elementos são silenciados; onde este discurso tem lugar, que posições de sujeito são ocupadas, como os atores se movimentam nessas posições ideologicamente definidas; quem fala, que espaços ocupa.

Os sentidos de um texto variam conforme as estratégias postas em funcionamento na construção do discurso, a constituição dos sujeitos que falam e dos sujeitos que lêem ${ }^{6}$, o meio em que o texto se materializa e as relações de poder envolvidas.

"O sentido é assim uma relação determinada do sujeito - afetado pela língua - com a história. É o gesto de interpretação que realiza essa relação do sujeito com a língua, com a história, com os sentidos. Esta é a marca da subjetivação e, ao mesmo tempo, o traço da relação da língua com a exterioridade: não há discurso sem sujeito. Ideologia e inconsciente estão materialmente ligados. Pela língua, pelo processo que acabamos de descrever" (ORLANDI, 2001: 47).

A construção dos sentidos, portanto, está intimamente relacionada aos interlocutores do discurso. Os sentidos se dão de acordo com as posições ideológicas que estão em jogo no processo de produção das palavras. 
Os sentidos das palavras têm relações com as formações discursivas em que estão inseridas. "A formação discursiva se define como aquilo que numa formação ideológica dada - ou seja, a partir de uma posição dada em uma conjuntura sócio-histórica dada - determina o que pode e deve ser dito" (ORLANDI, 2001: 43).

As formações discursivas não são percebidas nitidamente pelos sujeitos do discurso. Elas são verificadas no decorrer do processo de Análise do Discurso. Os enunciados e as formações discursivas a que pertencem são analisados correlativamente. Assim, no processo de Análise do Discurso, dá-se o desvelamento de um jogo de relações. As formações discursivas não são imóveis, fechadas, elas se definem nas suas relações com outras formações discursivas. As palavras recebem seus sentidos nas formações discursivas e nas relações em que estão inseridas. São as formações discursivas que determinam o que pode ser dito em determinada circunstância.

Para a Análise do Discurso, quanto à enunciação, todo texto é heterogêneo. Bakhtin (1986) diz que a enunciação é o resultado da integração de dois indivíduos. Segundo o autor, mesmo na ausência de um interlocutor real, ele pode ser substituído por um representante do grupo social.

A linguagem é tratada por Bakhtin como inerentemente dialógica. A figura do outro é imprescindível na construção do discurso, pois não se pode pensar o homem fora de suas relações. "Toda palavra serve de expressão a um em relação ao outro. Através da palavra, defino-me em relação ao outro, isto é, em última análise, em relação à coletividade. A palavra é uma espécie de ponte lançada entre mim e os outros" (BAKHTIN, 1986: 113).

O diálogo é a condição da linguagem e do discurso, mas existem textos monofônicos e polifônicos, de acordo com as estratégias discursivas empregadas. "Nos textos polifônicos, os diálogos entre discursos mostram-se, deixam-se ver ou entrever; nos textos monofônicos eles se ocultam sob a aparência de um discurso único, de uma única voz. Monofonia e polifonia são, portanto, efeitos de sentido, decorrentes de procedimentos discursivos, de discursos por definição e constituição dialógicos. Nos textos polifônicos escutam-se várias vozes, nos monofônicos uma apenas, pois as demais são abafadas” (BARROS, 1999: 36).

Ducrot utiliza-se da noção de polifonia de Bakhtin para diferenciar um sujeito enunciador de um locutor. Para ele (1987: 182), o locutor é "um ser que é, no próprio sentido do enunciado, apresentado como seu responsável”.

“(...) o locutor, designado por $e u$, pode ser distinto do autor empírico do enunciado, de seu produtor mesmo que as duas personagens coincidam habitualmente no discurso oral. Há de fato casos em que, de uma maneira quase evidente, o autor real tem pouca relação com o locutor, ou seja, com o ser apresentado, no enunciado, como aquele a quem se deve atribuir a responsabilidade da ocorrência do enunciado" (DUCROT, 1987: 182). 
O enunciador é a figura responsável pela produção de sentidos no enunciado, que mostra $o$ ponto de vista de onde se posiciona o locutor. "Chamo "enunciadores" estes seres que são considerados como se expressando através da enunciação, sem que para tanto se lhe atribuam palavras precisas; se eles "falam" é somente no sentido em que a enunciação é vista como expressando seu ponto de vista, sua posição, sua atitude, mas não, no sentido material do termo, suas palavras" (DUCROT, 1987: 192).

O locutor, responsável pelo enunciado, dá existência, através deste, a enunciadores cujos pontos de vista e cujas atitudes ele organiza e assimila. "Direi que o enunciador está para o locutor assim como a personagem está para o autor" (DUCROT, 1987: 192). O locutor pode ser comparado a um narrador, que é dado como a fonte de um discurso. Mas as atitudes expressas no discurso são atribuídas a enunciadores, que mostram seus pontos de vista no texto. Isso quer dizer que locutores diferentes podem ser veículos de um mesmo enunciador.

\section{Reflexões sobre o discurso de Datena}

José Luiz Datena, no decorrer do Brasil Urgente, tem uma postura que não é comum por parte da apresentação de um programa jornalístico. O apresentador tem um estilo completamente opinativo e profere julgamentos a todos aqueles que ele achar que precisam ser analisados no ar.

O público do programa Brasil Urgente presencia, em cada edição, a demonstração de um conjunto de características espetaculares. A exposição de detalhes do cotidiano da vida humana é comum no programa. O

apresentador comenta e analisa a maior parte dos fatos apresentados, mostrando-se como um juiz hábil a avaliar as relevâncias dos acontecimentos sociais.

Entre os alvos mais comuns dos comentários de Datena estão os políticos brasileiros, a Justiça e as autoridades de uma maneira geral. Assim, com a observação do desenrolar do Brasil Urgente e das atitudes exageradas do apresentador, nos detemos neste artigo na observação dos principais sentidos instituídos nas falas de Datena que caracterizam os políticos, a Justiça e a ordem social.

Por uma opção metodológica, mesmo levando em consideração que o discurso do Brasil Urgente é notavelmente polifônico e que estamos diante do discurso de diversos locutores, resolvemos nos deter somente na observação da produção de sentidos das falas do apresentador Datena ${ }^{7}$. Também por opção metodológica, decidimos tomar somente uma edição do Brasil Urgente para análise, a qual foi ao ar no mês de maio de 2006.

\section{1- Políticos}

No decorrer do programa, Datena faz diversos comentários sobre a atuação dos políticos e de seus trabalhos. Fica visível no discurso do apresentador a caracterização dos políticos como corruptos e como 
preocupados unicamente com interesses pessoais, com suas próprias finanças e em se valer do poder público para ter benefícios.

“Ta cega demais, "né”! Nestes blocos políticos, vamos enxergar nossos políticos preocupados mais em se defender das falcatruas que fizeram com o cooperativismo, absolvendo mais de 10 pessoas do mensalão, do que tocar este pacote de leis que tornasse a justiça brasileira mais justa, para que ela fosse aplicada com justiça porque isso é um absurdo [...]”.

“O sujeito rouba ambulância. O serviço público de saúde já é uma droga, uma porcaria, e meter a mão em ambulâncias e ficar solto porque tem e pretende logo meter a mão no dinheiro do povo não tem problema nenhum, a justiça está cega [...]”.

“[...] se rouba ambulância, mete a mão em dinheiro do povo, mensalão, ainda estão discutindo lá que não houve mensalão. Como não houve?"

"Vamos parar de ser hipócritas neste país. Somos todos cegos neste país. Essa é a dura realidade, dura realidade, como não houve mensalão e ficam se absolvendo ainda do cooperativismo total, não!”

“[...] estamos precisando colocar criminosos na cadeia neste país. Não pode cometer um crime destes! Aquele Igor, que está foragido porque tinha de se apresentar dali a quatro horas matou a mulher grávida. Os caras estão até roubando ambulâncias, quantas! Tantos políticos meteram a mão no dinheiro do povo. Quer dizer todos nós estamos cegos? Até quando nós iremos agüentar isso aí?"

\section{2- Justiça}

No discurso de Datena é reiterada constantemente a incompetência da Justiça, a qual é definida como ineficiente e como não apta a resolver os problemas sociais. Para o apresentador, a Justiça brasileira é "cega" por não conseguir resolver as problemáticas vigentes no país.

“Oh gente! A justiça é cega, mas não pode ser tão cega assim. Tanto há juristas que acham que a decisão do magistrado poderia ser diferente. Concorda comigo ou não? Isso é um absurdo. A justiça é cega, mas não pode ser tanta. É cega, é para os pobres aqui no Brasil, pobre está ferrado!" 
"O caso deste cara estar na cadeia. Agora só falta o caso da Suzane Richthofen sair da cadeia e usar a herança dos pais, que ela mandou matar com aqueles dois vigaristas daqueles Cravinhos. A justiça é cega, mas tem que enxergar algumas coisas que são evidentes, são claras [...]”

“[...] como é que esse cara não pode representar perigo para a sociedade, como, como que não pode representar perigo para sociedade: deu um tiro na Sandra e depois deu outro tiro no ouvido para matar mesmo. A qualquer momento esse cara pode entrar aqui e dar um trio na minha cabeça, porque estou metendo o pau nele. Ele é extremamente violento e assassino. Como esse cara respondeu o crime em liberdade e como ele pode ter saído pela porta da frente? Oh! Gente a justiça é cega, mas não pode ser tão cega assim. Tanto há juristas que acham que a decisão do magistrado poderia ser diferente. Concorda comigo ou não?”

"A justiça tem que ser cega com lealdade, não cega deste jeito. Ora a justiça pode ser cega, mas os juízes podem enxergar. Concordam comigo ou não?"

"Isso é um absurdo! A justiça é cega, mas não pode ser tanta. É cega, é para os pobres aqui no Brasil. Pobre está ferrado!"

\section{3 - Falta de ordem social}

A ordem social é um questionamento constante de Datena. Fica evidente no discurso do apresentador que ele acredita que vivemos em meio a um “caos”, que é resultado da omissão das autoridades.

“Aqui você pode articular o assassinato do seu pai e de sua mãe e ficar livre por uns tempos, aqui você pode matar sua mulher grávida e você responde a pena em liberdade e pode fugir como o Igor; aqui você pode mexer no dinheiro do povo e pode até usar este dinheiro depois que descobrirem que você é um ladrão, semvergonha, safado, mas se você roubar shampoo, manteiga, aí você está ferrado, boné então é o caso deste garoto [...]"

“[...] a mesma lei que soltou foi a lei que mandou prender, dá para entender o que estou falando?”

“O sujeito rouba ambulâncias. O serviço público de saúde já é uma droga, uma porcaria, desse país e meter a mão em ambulâncias e ficar solto porque tem [...] meter a mão no dinheiro do povo não tem problema nenhum, a justiça está cega [...]". 
“Aqui você pode articular o assassinato do seu pai e de sua mãe e ficar livre por uns tempos, aqui você pode matar sua mulher grávida e você responde a pena em liberdade e pode fugir como o Igor. Aqui você pode mexer no dinheiro do povo e pode até usar este dinheiro depois que descobrirem que você é um ladrão, semvergonha, safado, mas se você roubar shampoo, manteiga, aí você está ferrado, boné então é o caso deste garoto."

“[...] meter a mão no dinheiro do povo não tem problema nenhum. A justiça está cega, ela deveria ser cega conforme a Deusa Temis, a Deusa grega. Como procedimento de justiça, tanto você ser jornalista, gari, advogado, tanto faz você ser presidente da república, se você cometeu um crime tem que ir para a cadeia [...]"

“[...] nós estamos ficando com a impressão clara e cristalina que o crime compensa [...]”.

\section{Considerações finais}

O programa Brasil Urgente tem como eixo principal as atitudes do apresentador Datena, o qual aproveita o espaço que tem no ar para fazer um verdadeiro show com direito a comentários exagerados e julgamentos acerca das atitudes dos membros da sociedade, das autoridades competentes, da polícia, justiça e políticos.

Datena atua como um verdadeiro juiz capaz de avaliar o que é certo e errado para a sociedade e para a criminologia e de avaliar as atitudes que a sociedade teve a respeito de determinada questão. O transcorrer do Brasil Urgente é uma mistura entre jornalismo e espetacularização, o que evidencia que o programa segue a tendência de muitos programas televisivos da atualidade, que é a exploração de elementos do cotidiano humano de forma espetacularizada. Datena explora verbalmente as brechas deixadas pelas autoridades e pelos políticos para ter espaço para dispensar críticas e reiterar sua condição de "juiz hábil a avaliar os acontecimentos sociais".

É visível a auto-referência por parte do apresentador, principalmente quando se trata da crítica às autoridades competentes. Também é perceptível no Brasil Urgente a ênfase ao espetacular, pois não é comum à atividade jornalística o julgamento dos atores sociais. Na medida em que discute questões acerca da sociedade, Datena questiona a presença das autoridades, a validade da Justiça e a atuação da polícia na solução dos problemas. É comum na fala do apresentador expressões como: "Cadê a polícia nessa hora?”; “A justiça é cega"; "A lei brasileira protege o bandido". Desta forma, o jornalista, ao questionar as atitudes das autoridades competentes, atribui para si a qualidade de justiceiro, de homem que tem a solução para o que está errado.

Em relação aos políticos, Datena deixa clara a sua opinião de que eles são corruptos, que praticam irregularidades e que desviam dinheiro público. Expressões como "meter a mão no dinheiro do povo é comum" 
e "são uns corruptos" são destinadas por Datena aos políticos do Brasil. Na medida em que questionamos a forma como Datena apresenta os políticos e as autoridades, não estamos querendo defendê-los. Sabemos que é bastante corrente por parte da sociedade o questionamento acerca das atitudes dos políticos. Só estamos questionando as práticas de um programa que se diz jornalístico e que se encontra na grade de jornalismo da emissora que o leva ao ar.

Assim, podemos dizer que o Brasil Urgente está longe de retratar a pauta social com objetividade e de levar em consideração a velha idéia da objetividade jornalística. Nas falas do apresentador fica visível sua opinião e seus julgamentos. O programa e o apresentador podem parecer justiceiros se olhados de maneira geral, mas com a observação da estrutura narrativa do programa e das falas de Datena, a idéia de o Brasil Urgente só se preocupar com o bem social é desbancada. Torna-se evidente que estamos diante de uma busca por audiência. 


\section{Referências bibliográficas}

BAKHTIN, Mikhail. Marxismo e filosofia da linguagem. 3.ed. São Paulo: Hucitec, 1996.

BARROS, Diana Luz Pessoa. Contribuições de Bakhtin às teorias do texto e do discurso. In: FARACO, Carlos Alberto (org). Diálogos com Bakhtin. 2 ed. Curitiba: UFPR, 1999.

BUCCI, Eugênio. O peixe morre pela boca. São Paulo: Scritta, 1993.

DUCROT, Oswald. O dizer e o dito. Campinas: Pontes, 1987.

FISCHER, Rosa Maria Bueno. O mito na sala de jantar: discurso infanto-juvenil sobre a televisão. Porto Alegre: Movimento, 1984.

MACHADO, Arlindo. A televisão levada a sério. São Paulo: SENAC, 2000.

ORLANDI, Eni. Análise do discurso: princípios e procedimentos. 3 ed. Campinas: Pontes, 2001.

PINTO, Ivonete. A dramatização no telejornalismo - Caras e bocas fazendo a notícia. Dissertação de mestrado defendida no Programa de Pós-Graduação em Comunicação da PUC-RS, 1998.

ROSÁRIO, Nísia Martins do. Televisão: simulação em tempo real e sedução em tempo integral. Verso e Reverso. Ano XV. No 32. 2001. São Leopoldo: Unisinos.

SILVA, Giane David da. A informação televisiva entre a realidade e a ficção. Disponível em: <http:// www.ufop.br/ichs/conifes/anais/LCA/clca01.htm>. Acesso em: 5 de dezembro de 2002.

SODRÉ. Muniz. Televisão e psicanálise. São Paulo: Ática, 1987.

SQUIRRA, S. Boris Casoy: O âncora no telejornalismo brasileiro. Petrópolis, RJ: Vozes, 1993.

WOLTON, Dominique. Elogio do grande público: uma teoria crítica da televisão. São Paulo: Ática, 1996.

WOLTON, Dominique. Internet, e depois? Uma teoria crítica das novas mídias. Porto Alegre: Sulina, 2003.

\footnotetext{
${ }^{1}$ Artigo apresentado no IX Seminário Internacional da Comunicação da Comunicação da PUC RS.

${ }^{2}$ Mestre em Comunicação e Informação pela Universidade Federal do Rio Grande do Sul; doutoranda em Comunicação da Pontifícia Universidade Católica do Rio Grande do Sul; docente da Universidade Federal de Santa Maria/ Unipampa São Borja - Rio Grande do Sul. E-mail: mmnegrini@yahoo.com.br.

${ }^{3}$ Dados retirados do site www.band.com.br/brasilurgente/, endereço eletrônico oficial do programa Brasil Urgente.

${ }^{4}$ Jornalista e atual apresentador do Brasil Urgente. Datena também foi apresentador do programa de mesmo gênero, Cidade Alerta, transmitido pela Rede Record de televisão e que hoje está fora do ar.

${ }^{5}$ Descrição do programa Brasil Urgente retirada do site oficial do programa.

${ }^{6}$ Considerando-se todo receptor, independentemente do veículo, como "leitor", e a leitura como um ato de produção de sentidos.

${ }^{7}$ Descrevemos as falas de Datena literalmente como elas foram proferidas pelo apresentador no programa.
} 